\title{
Performer Identifier
}

National Cancer Institute

\section{Source}

National Cancer Institute. Performer Identifier. NCI Thesaurus. Code C93982.

A unique symbol that establishes identity of the performer. 